\title{
Evolving Cultural Models of Mercury: From Minamata to the Anti-Vaccine Movement
}

Andrew Pearce Carter ${ }^{* \dagger}$

andrew.pearce.carter@gmail.com

* Abess Center for Ecosystem Science and Policy, University of Miami

${ }^{\dagger}$ Current affiliation: Center for Conservation Innovation, Defenders of Wildlife

$¥$ Current affiliation: Affiliate Faculty, Department of Environmental Science and Policy, George Mason University

\begin{abstract}
This article examines the cultural history of mercury as an environmental pollutant and toxic, with a particular focus on two historical phenomena: the Minamata Bay poisoning of the 1950s and its aftermath, and the American anti-vaccination movement of the early twentyfirst century. It provides a historical account of both events and applies a cultural models framework to argue that the former, along with the subsequent coverage of it and other environmental poisoning cases in the United States, helped create the latter. Cultural models are cognitively constrained and historically constituted, difficult to change, and may explain why human beings often make non-rational decisions and hold incorrect beliefs about physical phenomena even when they have been given correct information. While cultural models research has tended to focus on experimental and observational studies among small groups at single instances of time, this article offers the theory as a lens through which to investigate cultural history as well.
\end{abstract}




\section{INTRODUCTION}

A critical component of some industrial processes and an unwanted byproduct of others, mercury and its risks have been debated in one form or another for more than 2,000 years. Early alchemists saw mercury as a fundamental reagent of the cosmos, a spiritually imbued representation of the creative energy of the universe, and a medicinal agent both potent and dangerous. From alchemy to medicine to science, and back to alchemy again, mercury has held a unique place in the cultural imagination, as a sign of power and peril, a symbol of both industrial optimism - clean, fluid and silvery, it visually reified the space age aesthetic - and later a darker symbol of the costs of industry as an environmental pollutant which could damage human brains, particularly those of the young and vulnerable.

The article below first provides brief summaries of mercury's physical, chemical, and biological characteristics, as well as its historic use by human societies from prehistory into the twentieth century. It then provides a detailed historical account of the Minamata Bay poisoning in Japan in the 1950s, the most prominent mercury poisoning event, and its aftermath both in that country and in the United States, placing that account in the context of wider environmental concerns and anxieties through the second half of the twentieth century. The article then examines the anti-vaccine movement in the United States during its resurgence of the late 1990s through the present, particularly as it relates to the mercury-based vaccine preservative, thimerasol, arguing that conceptions of mercury risk among anti-vaccine activists and authors was influenced by not only environmental poisoning events but also the governmental and industry responses to those events, with the Minamata poisoning the most prominent such event.

Therefore, if at any given period and in any given culture understanding of mercury must by necessity involve the use of mental models that are historically situated and culturally 
constituted and communicated, and can provide, if not a rigid naturalistic methodology by which to explain them, an interpretive standpoint which to explore the transitivity of objects of knowledge.

Thus, the medieval alchemical promises of mercury may be echoed in the quack medicine of the nineteenth and twentieth centuries in the United States, promises which still manifest in grey market mercurial medicines found in the botanicas of American cities. A young boy who saw the tragic photographs of the Minamata mercury poisoning victims would years later spearhead laws and regulations to limit mercury risk in this country, first as a Senator and later as President of the United States. Awareness of Minamata and growing media attention to the mercury in fish through the 1970 s onwards created a sense of dread that may be a contributing factor in the rise of the movement to reject vaccines containing the mercury compound thimerasol, causing a health crisis in the United States and other countries where that movement took hold. ${ }^{1}$

\section{MERCURY: PHYSICAL MANIFESTATIONS}

Mercury is a heavy element, one of only two that is liquid at room temperature in its elemental form. It is ubiquitous in the environment, including in the ambient air around us, though typically at harmless levels. Relatively unreactive and insoluble in water, atmospheric mercury tends to remain in the atmosphere for fairly long periods of time, typically six months to a year, but when it is oxidized, e.g. has one or two of its valence electrons removed through chemical processes, its solubility dramatically increases and it is quickly scavenged from the

\footnotetext{
${ }^{1}$ Barack Obama. Dreams From My Father: A Story of race and inheritance. (New York, 2007;
} orig. pub. 2004). 
environment and deposited onto the earth's surface. When oxidized forms of mercury (typically referred to as inorganic mercury) enter aquatic and marine environments, they can be transformed through microbial processes into particularly toxic forms of organic mercury, with methylmercury being the chemical form of greatest concern. Organic mercury tends to biomagnify and bioaccumulate through marine and aquatic ecosystems, usually becoming significantly more concentrated as it moves up the food chain.

While the dangers of mercury compounds from point source mercury poisoning events have been clearly shown in places like Minamata (described in detail below), a number of studies have also demonstrated a significant correlation between the consumption of naturally highermercury seafood by pregnant women with neurodevelopmental issues in their children. While there is significant scientific uncertainty as to how mercury moves and transforms through the environment, and the levels at which it becomes dangerous, the overwhelming scientific consensus is that mercury at some level is dangerous and that levels of mercury in the environment have increased significantly due to increased human sources such as coal combustion and artisanal gold mining. ${ }^{2}$

\section{MERCURY IN HISTORY}

The most common compound of mercury on earth is mercuric sulfide, known as the red mineral cinnabar. Early modern humans encountered cinnabar in areas of volcanic activity,

${ }^{2}$ Robert P. Mason et al., "Bioaccumulation of Mercury and Methylmercury," Water, Air, and Soil Pollution 1995; Philippe Grandjean et al., "Cognitive Deficit in 7-Year-Old Children with Prenatal Exposure to Methylmercury," Neurotoxicology and Teratology 19 (1997):417428. 
where the bright red mineral would have shown clearly against the darker rocks surrounding it. This deep, rich red made it appealing to early artists, and cinnabar-based pigments were used as early as 8,000 BC for painting, including on the walls of the world's oldest urban settlement, Çatal Hüyük, in modern-day Turkey. In addition to its vivid color, cinnabar has another unusual property: globules of liquid mercury can form on the surface of high-mercury deposits, sometimes naturally if the mercury concentration is high enough, but also through intense heat applied to the mineral. A number of ancient cultures developed ways to extract mercury from cinnabar, typically involving evaporating elemental mercury, then capturing and cooling it so it would precipitate in its pure form. The secret of mercury production was discovered (or rediscovered) throughout the ancient world, including by the ancient Chinese, Persians, Assyrians, and Mayans, and often worked mercury into complex systems of spirituality and mysticism. In addition to its (usually fictitious) alchemical or health characteristics, early metalworkers found elemental mercury could amalgamate both silver and gold, seeming to dissolve them; heating the amalgam would evaporate the mercury, leaving the silver or gold in a purer and more recoverable form, a method is still used in the present to extract gold from gold ore, particularly in the developing world, a phenomenon that has grown in recent years due to increases in the price of gold. ${ }^{3}$

${ }^{3}$ P.A. Lins \& W.A. Oddy, "The Origins of Mercury Gilding," Journal of Archaeological Science 2 (1975), 365-373; D.M. Pendergast, “Ancient Maya Mercury,” Science 217, no. 4559 (1982), 533-35; G. Rapp, Archaeomineralogy (Berlin, 2009), 242; A. Cheak, Alchemical Traditions: From Antiquity to the Avant-Garde (Melbourne, 2013), 207-8; L.M. Principe, The Secrets of 
Even while alchemists and mystics worked mercury into elaborate cosmological theories, and ancient metalworkers used it in their trade, there was a widespread awareness of the dangers that mercury could pose. Galen of Pergamon, a Greek physician of the second century A.D., considered by some second only to Hippocrates in his influence on the history of medicine, considered mercury poisonous. These debates were still raging in Renaissance Europe; when Paracelsus, the founder of the field of toxicology, set forth his maxim that "[s]olely the dose determines that a thing is not a poison" he then used mercury as an example of such a substance that was poisonous at higher doses, though he himself prescribed it therapeutically. ${ }^{4}$

European enthusiasm for mercury waned as alchemy gave way to chemistry, and the frequently confused and quasi-mystical medicine of the Medieval and Renaissance gave way to the more scientifically rigorous (and generally less deadly) medical practice of the nineteenth century, though mercury remained a popular tool in the clinician's toolbox during that period. By the turn of the century, however, clinical evidence of the dangers of mercury, the lack of evidence of significant health benefits for its use, and the availability of alternative antibiotics had driven it largely outside mainstream medicine. This process was likely helped by the professionalization of the medical profession in the United States and abroad around that time,

Alchemy (Chicago, , 2013), 35-37; N. Sivin, "Chinese Alchemy and the Manipulation of Time," Isis 67 (1976), 513-526.

${ }^{4}$ R.M. Swiderski, Quicksilver: A History of the Use, Lore and Effects of Mercury (Jefferson, NC, 1997); W.B. Deichmann et al., "What Is There That Is Not Poison? A Study of the Third Defense by Paracelsus," Archives of Toxicology 58 (1986), 207-213. 
and stronger drug safety regulations, both of which weakened the market for the kind of medication promoted by the amateur, mercury-loving quack pharmacist. ${ }^{5}$

This did not, of course, stop mercury poisoning: mercury bichloride tablets were still often used as a germicide prior to the advent of modern antibiotics, and the early 1910s saw a well-publicized epidemic of deaths from such tablets, with a reported seventy eight cases occurring in New York in a single eight month period in 1914. Many of the newspaper accounts reported many victims had taken the tablet accidentally, mistaking them for "headache tablets,"

though at least some of those reports may have been phrased as such to preserve the reputation of the deceased, as mercury bichloride was still commonly used at the time to treat syphilis, despite the availability of the more effective Salvarsan.

\section{TOXIC LANDSCAPES: MINAMATA AND THE HIDDEN COSTS OF THE INDUSTRIAL AGE}

By the middle of the twentieth century mercury had been displaced in most medicine, though its unique chemical properties made it increasingly useful to the chemical industry, particularly for things like the chlor-alkali industry, in pesticides, and to the creation of explosives for use in construction or war. The physicality of liquid mercury matched the optimism of the post-war years; clean and fluid, it seemed reflective and symbolic of change, speed, and clean and sleek, fluid and progressive. Sculptor Alexander Calder created a modernist mercury fountain for the Spanish pavilion at the 1937 World Exposition in Paris. But

${ }^{5}$ S.O. Habershon, On the Injurious Effects of Mercury in the Treatment of Disease (London, 1860); M.I. Wilber, “The Evolution of Laws Regulating the Sale and Use of Poisons," The Journal of the American Pharmaceutical Association (1912), 1259-1261. 
technological optimism over the rapid development of technology and industry following the war would soon give way to more public pessimism as the costs of that development began to be incurred. Like many other useful industrial chemicals, mercury would show a frightening dark side. $^{6}$

\section{THE MINAMATA BAY POISONING: 1953-1968}

Minamata remains the dominant and defining event in the historical narrative over the perils caused by environmental mercury. Located in Kumamoto Prefecture, Japan, on the coast of the island of Kyushu, the city of Minamata was the site of Chisso Corporation, a large, politically powerful petrochemical manufacturer. In 1953 residents of the small fishing communities surrounding Minamata Bay started noticed something strange: local birds appeared to be having problems with coordination, frequently falling from perches or flying into buildings, while local cats suffered similar problems with tremors and other unusual movements, leading to some observers to refer to "dancing cat disease."7

The mysterious condition did not stay limited to birds and cats, as local fishers and their families soon began to suffer similar symptoms. Minamata fisherman Sohachi Hamamoto woke up one morning hard of hearing and having difficulty with movement and balance; his condition worsened every day until he had to be hospitalized and continued to deteriorate in the hospital

${ }^{6}$ M. Daniel, "Between Paris and New York: Fountains, Fluidity, Politics,” in Borchardt-Hume (ed.), Alexander Calder: Performing Sculpture (2016), 50-51.

${ }^{7}$ D.E. Kaplan \& A. Dubro, Yakuza: Japan's Criminal Underworld (Berkeley, 2012), 164; N. Huddle \& M. Reich, Island of Dreams: Environmental Crisis in Japan (Cambridge, 1987), 107. 
until he died. Even more heartbreaking was the impact on the child victims. One 5-year old girl was brought in suffering symptoms of extreme brain damage, including an inability to walk and incoherent speech; her two-year-old sister joined her in the hospital several days later with the same symptoms. ${ }^{8}$

Physicians and researchers initially examining the victims offered various explanations to the sufferers (and their parents), including cerebral palsy, malnutrition, and infectious disease, but by 1956 the number of victims had reached the point where medical authorities realized that they were suffering from a common malady, almost certainly some sort of environmental contaminant. The presence of the Chisso plant, of course, suggested pollution as a possible culprit; locals fishing in the Bay had long been aware of the environmental damage caused by plant effluent, as the plant's drainage channel emanated a rotting stench, and the natural biota clinging to boat hulls would be stripped away if they moored their boats near it. Indeed, the plant had been paying local fishers token payments to compensate them for the damage caused to fishing areas since 1925, but the new poisoning was starkly different from the environmental degradation with which the fishers were familiar. ${ }^{9}$

The impact of this sudden "Minamata Disease" was horrific. Forty percent of the victims died, and autopsies showing brains that had in some cases been eaten away until they looked like sponges. The illness overwhelmed the abilities of the local health authorities, and a committee of medical researchers from Kumamoto University were called in to investigate the issue. They

\footnotetext{
${ }^{8}$ W.E. Smith \& A.M. Smith, Minamata (New York, 1975), 28, 79-80.

${ }^{9}$ B. Walker and W. Cronon, Toxic Archipelago: A History of Industrial Disease in Japan
} (Seattle, 2011), 147. 
quickly developed numerous theories as to Minamata Disease's cause, including that it was caused by some infectious disease, or environmental or food contaminant. However, by early 1959 the scientific consensus had developed that the symptoms most closely resembled the effects of heavy metal poisoning as the culprit, and after researchers considered and rejected manganese, thallium, and selenium as possible contaminants, they settled on organic mercury as the most likely cause of the disease by the middle of the year. ${ }^{10}$

The Chisso Corporation, aided by other industry actors, launched an effective - and occasionally violent - counteroffensive to deflect blame and introduce doubt in the researchers' findings that mercury-laden effluent from its factory was the cause of Minamata disease. They were supported, in part, by the local residents' loyalty to the company; Chisso employed a substantial portion of them, and Japanese cultural norms demanded a loyalty to one's company that turned many plant employees against their fisher neighbors. Company loyalty would also silence a Chisso company doctor, Hajime Hosokawa, who had had found that when he fed plant effluent to a cat, it developed the same symptoms as the victims. When he reported the result to management he was ordered to stop. Loyalty to the company kept him quiet for a decade, until he finally testified, from his deathbed, about the results of his experiment - and the fact that he had informed the company of those results. ${ }^{11}$

${ }^{10}$ S. Sugiyama, "Minamata Disease: Interaction Between Government, Scientists, and Media," in Fujigaki (ed.), Lessons from Fukushima: Japanese Case Studies on Science, Technology and Society (2015), 125-126.

${ }^{11}$ Smith, Minamata, 122-3; Sugiyama, "Minamata Disease: Interaction Between Government, Scientists, and Media," 127-129. 
Cultural attitudes towards both disease and fishers' peripheral role in Japanese society also became barriers to the fishers' quest for both explanation and compensation. In Japanese society fishers lived "outside mainstream political and economic power." 12 One Minamata victim, Eiko Sugimoto, was almost killed when a man tried to push her off a cliff, and disputes broke out not only between the unafflicted and the afflicted, but also between victims who wished to negotiate directly with the company for redress and those willing to mediate through government channels. ${ }^{13}$

By 1958 increasingly frustrated victims and their families, often treated as pariahs by their neighbors, publicly demanded not only better pollution controls at the factory but also compensation, demonstrating at the factory. Eventually, in 1959, Chisso agreed to sign small indemnity contracts with victims which appeared to quiet complaints for the next decade, and installed a "Cyclator" which the company (falsely) claimed would clean the effluent of mercury. They also diverted effluent to sedimentation pools, and through them into a river north of Minamata Bay, flushing much of the mercury into the larger Shiranui Sea of which Minamata Bay was one inlet. However, the victims continued to suffer, and the company continued to

${ }^{12}$ Brett and Cronon, Toxic Archipelago: A History of Industrial Disease in Japan, 141.

${ }^{13}$ Smith, Minamata, 122; T. Gill and T. Kazuko, "New Lives: Some Case Studies of Minamata," The Asia-Pacific Journal 12 (2014). Increased willingness to challenge industrial and government institutions in Minamata also coincided with a growing environmental movement in Japan through 1960s and 1970s connected to transnational environmental movements of the time, see S. Avenell, "The Borderless Archipelago: Toward a Transnational History of Japanese Environmentalism," Environment and History 19 (2013), 397-425. 
discharge methylmercury-laced effluent. The anger of the victims, their families, and supporters would be rekindled in 1966 when on the other side of Japan, in Niigata Prefecture, a similar poisoning event occurred when a chlor-alkali plant owned by a large chemical firm, Showa Denko, released methylmercury-containing effluent into the Agano River. The disease followed the same course as in Minamata, including at first abnormal cat behaviour, and ended up with human victims, who unlike Minamata fishers lived in a community far enough from the plant that they faced little local political or community opposition to their claims. ${ }^{14}$

As community anger in Minamata once again grew in response to Niigata, likely aided by a growing environmental movement in Japan, Chisso Corporation not only ignored or denied the accusations, but fought back with hired "security" companies that had ties to the Japanese underworld. Violence instigated by those security companies as well as by allied ultranationalist groups broke out on numerous occasions, including at one shareholder meeting where a prominent Associated Press photojournalist, W. Eugene Smith, was severely beaten, leading to partial blindness and damage to several vertebrae. Eventually, however, a Japanese federal judge found the Chisso Corporation guilty of gross negligence, ordering compensation be paid. In 2012 there were still 2,273 recognized patients suffering from the effects of the poisoning, though many more residents have sought to be recognized by the government as victims. ${ }^{15}$

\footnotetext{
${ }^{14}$ Smith, Minamata, 117-120. The company would ultimately stop discharging methylmercurylaced effluent in 1968, when technological advances made it unnecessary.

${ }^{15}$ Kaplan, Yakuza: Japan's Criminal Underworld, 164-168; Smith, Minamata, 95; Avenell, “The Borderless Archipelago: Toward a Transnational History of Japanese Environmentalism,”; M.
} 
While the events at Minamata were covered extensively in the Japanese press, isolated reports were slow to appear in the Western press through the 1950s and 1960s, including in academic journals. A special article on "Minamata Disease" appeared in the September 20, 1958 issue of The Lancet, describing the outbreak and offering a number of possible contaminants that may have caused it, including methylmercury. A later 1959 issue of the journal Nutrition Reviews by the same authors summarised Japanese-language reports of the symptoms suffered by Minamata villagers, but also identified mercury poisoning as just one possible explanation for the symptoms observed. Other than sporadic reports in the academic health literature, however, the poisoning event went largely unnoticed in the Western English-language press. Though the researchers at Kumamoto University had concluded that organic mercury poisoning caused Minamata Disease by 1959, and their accounts reached the English-language medical literature as early as 1962, it was not until 1970 when the risks of environmental mercury would reach the public stage in force. ${ }^{16}$

Aoyama and M.J. Hudson, "Minamata as Negative Heritage," Pacific Geographies 40 (2013), 23-28.

${ }^{16}$ Sugiyama, "Minamata Disease: Interaction between Government, Scientists, and Media"; D. McAlpine and S. Araki, “M inamata Disease: An Unusual Neurological Disorder Caused by Contaminated Fish," The Lancet 272 (1958): 629-631; D. McAlpine and S. Araki, "M inamata Disease: Late Effects of an Unusual Neurological Disorder Caused by Contaminated Fish," Archives of Neurology (1959), 78-86; T. Takeuchi et al., "A Pathological Study of Minamata Disease in Japan," Acta Neuropathologica 2 (1962), 40-57. 


\section{THE ECOTOXICOLOGICAL TURN IN ENVIRONMENTAL SCIENCE}

At around the same time that Japanese residents of Kumamoto were coming to grips with Minamata Disease, the effects of mercury were being observed half a world away, in Sweden. There, the victims of mercury in the landscape were less noticeable than in Minamata. Beginning in the mid-1950s Swedish authorities had begun to discover numerous animals, primarily birds, in the countryside, lying dead with signs of poisoning; subsequent chemical analyses showed high levels of mercury. Swedish scientists therefore spearheaded a research program into environmental mercury. In 1969 Jensen and Jernelöv established via a laboratory study that oxidized mercury could be methylated in sediments. Subsequently, other researchers determined that methylmercury could then be accumulate through the food chain, noting that "hazards rapidly increase towards the top of the chain.",17

By this time period both scientists and the general public had become aware not only of the fact that environmental contaminants could cycle through nature and ultimately harm human beings, but also that this transfer could be mediated through biological and ecological processes, largely though not completely through the work of Rachel Carson, as well as pioneering French scientist Rene Truhaut who coined the study "ecotoxicology." While human beings had long connected health hazards with poor environments, such connections tended to be made only when the environment exhibited something visible or olfactory, for example with the "miasma" theory of disease which saw sickness transmitted by the noxious gases of swamplands. Carson,

\footnotetext{
${ }^{17}$ S. Jensen \& A. Jernelöv, "Biological Methylation of Mercury in Aquatic Organisms," Nature 223 (1969); K. Borg et al., "Experimental secondary methyl mercury poisoning in the goshawk (Accipiter G. Gentilis L.)," Environmental Pollution 1 (1970), 103.
} 
Truhaut, and other scientists of the era had managed to translate to the public the fact that harmful contaminants could impact them unseen, and inspired a burst of research into the ecological dynamics of such contaminants. While early concerns focused on DDT and other pesticides, mercury would also soon loom large in the public imagination in the United States. ${ }^{18}$

\section{MERCURY AND THE AMERICAN CONSCIOUSNESS: 1970 ONWARDS}

Though sporadic reports of Minamata made it to specialized outlets in the United States, the mainstream media paid little attention until 1970. However, before the news of Minamata had reached the United States public consciousness, the country had its own mercury poisoning outbreak, though on a smaller scale than had been seen in Japan or Iraq. In October of 1969 Ernest Huckleby, a 47-year-old father of seven who worked as a school custodian, slaughtered one of the hogs he had been raising to supplement his income for food (Goodrich, 1970). A few months later, he and the members of his family who had eaten the meat, including his pregnant wife, began to suffer serious side effects. Hardest hit were three of his children, particularly 8year-old Ernestine Huckleby who suffered quadriplegia, blindness, seizures and severe mental retardation. As had happened with the Minamata victims, doctors were initially unable to identify the cause of the symptoms, but by January had identified the cause of the disease as mercury poisoning, leading to a local panic and the quarantine of hogs and impoundment of potentially contaminated grain. The Huckleby incident made the national media in February of 1970, making the New York Times on the first of the month, and televised on the NBC evening

news on February 17. Huckleby's 8-year-old daughter Ernestine would become the most tragic

${ }^{18}$ R. Carson, Silent Spring (New York, 1962); R. Truhaut, "Ecotoxicology: Objectives, Principles, and Perspectives," Ecotoxicology and Environmental Safety 1 (1977), 151-173. 
victim of the incident; National Geographic published a heartbreaking picture of the blind, mute, and motor-impaired girl, eyes wide (but unseeing) as she clutches a stuffed bear. ${ }^{19}$

On 2 April 1970, not too long after the Huckleby poisoning had reached national awareness, the American embassy in Ottawa, Canada, notified the State Department that the Canadian government had discovered serious mercury contamination in boundary waters between the two countries, particularly Lake St. Clair on the Ontario-Michigan border. Federal and state agencies in the United States quickly responded, collaborating on a comprehensive sediment and fish sampling study across numerous boundary waters between the two countries, with dismaying results: the Federal Water Quality Administration issued a report noting that mercury contamination was an "international and interstate environmental problem of major scope." The months following that report showed the agency had understated the problem. Throughout the summer of 1970, state and federal agencies looked for mercury in water bodies around the country, and to their distress, usually found it. At one congressional hearing in 1970, the deputy director of Michigan's Department of Natural Resources cited Minimata, Niigata, and Sweden when remarking on the "paradox" of "the lack of knowledge and apprehension over

${ }^{19}$ L.E. Davis et al., "Methylmercury Poisoning: Long-Term Clinical, Radiological, Toxicological, and Pathological Studies of an Affected Family," Annals of Neurology 35 (1994), 680-688; J. Goodrich, “Tragic Irony of Family Stricken With Poison,” Jet March (1970). The picture of Ernestine Huckleby appeared in a special National Geographic issue called As We Live and Breathe: The Challenge of Our Environment in June, 1971. 
mercury" in the United States. Numerous environmental managers remarked on the suddenness of the awareness that environmental mercury was even a problem. ${ }^{20}$

Primed by the Hucklebys and the discovery of mercury saturation in American waters, the public then was faced with a fuller picture of the tragedy of Minamata. The government and media, and to a lesser extent the public, had become aware of the Minamata poisoning, but accounts were typically brief. ${ }^{21}$ But in 1970 Associated Press photographer W. Eugene Smith, who along with his wife Aileen had spent three years in Minamata, living among and chronicling the lives of the victims, brought the tragedy to the American public in a far more emotionally salient way. On June 2, 1972, shortly after the brutal attack Smith suffered, Life Magazine published a photo essay of the Minamata outbreak in their June 2 issue, not only describing the severe physical and mental impacts of Minamata Disease outbreak he and his wife had witnessed, but also showing the readers in vivid, oftentimes disturbing detail what the villagers had suffered. His photograph Tomoko Uehara in Her Bath (Smith, 1972), showing a mother bathing her severely disabled daughter, would become world famous, and has been referred to as "the pietà of our industrial age". ${ }^{22}$ One young American boy emotionally moved by it would later

${ }^{20}$ U.S. Congress Committee on Commerce, Subcommittee on Energy, Natural Resources, and the Environment, "The Effects of Mercury on Man and the Environment," $91^{\text {st }}$ Cong. (1970).

${ }^{21}$ See, e.g., A. Salpukas, "Mercury Spills Imperil Erie Fisheries," The New York Times, May 11 (1970); T. Oka, "Sato Plans Action to Meet Pollution Crisis in Japan," The New York Times May 29 (1970).

22 J. Morris, Get the Picture: A Personal History of Photojournalism (Chicago, 2002) 275; G. Thornton, "Photography View," The New York Times May 11 (1975). 
be the driving force behind substantial legal and regulatory efforts to reduce mercury pollution, and as President would ratify the Minamata Convention on behalf of the United States. ${ }^{23}$

Only days after Smith's essay was published, copies of the magazine were rushed to Stockholm, Sweden, where representatives of 113 different states were convening for the first United States Conference on the Human Environment. The issue made a significant impression on participants at the conference. ${ }^{24}$ However, the communities hit by Minamata Disease had also sent their own ambassadors in person - including Shinobu Sakamoto, a wheelchair-bound victim of the poisoning whose photograph had also appeared in Smith's photo essay alongside Tomoko's; fifty years after suffering the effects of the poisoning, Sakamoto still advocates on behalf of the Minamata victims. ${ }^{25}$

If the American media had been caught unaware by environmental mercury risks, they made up for their lack of attention in the first few years of the 1970s. A 29 January 1971 Life Magazine article addressing mercury risks noted that in light of Minamata, Iraq, and the Huckleby incidents, "we should have been" more alert of mercury dangers. The United States government took some quick action to protect against environmental mercury. The sudden media attention regarding environmental mercury's health risks into the national consciousness continued through the 1970s. National Geographic ran a story in October of 1972 entitled

${ }^{23}$ Obama, Dreams from My Father: A Story of Race and Inheritance, 29.

${ }^{24}$ Thornton, "Photography View," 1975.

${ }^{25}$ K. Hirano, "Seminar Seeks to Shine Spotlight on Mercury-Linked Minamata Disease," Japan Times September (2016). 
"Quicksilver and Slow Death," noting the "sudden[]" awareness of mercury’s "double nature."26 In March of 1972, the American media also reported on a mercury poisoning event in Iraq, where 100-400 people died from eating wheat seed coated with a mercury fungicide. ${ }^{27}$

Most of the pollution control laws created in the 1970s included mercury among the numerous toxic substances they regulated, including the Clean Water and Clean Air Acts, the Toxic Substances Control Act of 1976 and the Comprehensive Environmental Response, Compensation, and Liability Act, more commonly known as Superfund. With the fungiciderelated poisoning events of Iraq and Sweden in recent memory, mercury-containing pesticides were an early target of the federal government. In 1970 President Nixon had transferred authority over pesticide regulation from the notoriously agribusiness-friendly Department of Agriculture to the nascent Environmental Protection Agency (EPA), which moved quickly to deregister a number of mercury-based pesticides, removing them from the market. ${ }^{28}$ The EPA also restricted emissions of mercury vapour under the Clean Air Act from sources such as chlor-alkali plants (the type that had poisoned Minamata Bay) and waste sludge and medical waste incineration. In 1974 the FDA changed a 0.5 ppm limit guideline for mercury in fish to an "action level,"

${ }^{26}$ J.J. Putnam, “Quicksilver and Slow Death,” National Geographic October (1972).

27 “Mercury Poisoning in Iraq is Said to Kill 100 to 400," The New York Times March 9 (1972).

${ }^{28}$ A. Carter, "Alchemical Rulemaking and Ideological Framing: Lessons from the 40-Year battle to Regulate Mercury Emissions from Electric Power Plants," Natural Resources Journal 58.2 (2018) 143. 
allowing the agency taking legal action to prevent sale of fish containing more, though a federal court forced the EPA to raise that limit to $1 \mathrm{ppm} .^{29}$

Though throughout the 1970s and 1980s the American media ran stories about environmental mercury's dangers particularly regarding seafood, but after the initial burst in the 1970s, such stories became somewhat rarer. For example, a search of the New York Times archive for "mercury and fish" retrieves 35 relevant stories between 1 January 1970 and 31 December 1979, but only three in the 1980s. Mercury's toxic risks had moved from sudden - and therefore frightening - risk to just one of many environmental contaminants that had been discovered to permeate through the industrial landscape. Public concern over the environment generally continued to run high, however. While media preoccupation with environmental issues may have waned at least somewhat from its Earth Day peak in the immediate years follow, proenvironmental attitudes overall in the United States appeared to have remained stable through the 1970s and 1980s, with a significant increase in the late 1980s and early 1990s. Certainly the late 1970s and early 1980s saw extensive media attention paid to environmental contaminant risks and hazards, most famously through the Love Canal controversy, but also through the Warren County PCB landfill protests in 1982, and the Bhopal disaster in India in $1984 .^{30}$

${ }^{29}$ U.S. v. Anderson Seafoods 1980.

${ }^{30}$ Though there is a relative lack of comprehensive survey data about environmental attitudes in the United States, the data that does exist suggests this pattern; see R.E. Dunlap, "An Enduring Concern,” Public Perspective 13 (2002) 10-14; T.A. Eberlein, Navigating Environmental Attitudes (New York, 2012) 50. 
Regarding mercury specifically, state governments continued to increase the number of mercury-based fish advisories covering their waters. Accurate aggregate mercury-based fish advisory data is difficult to find prior to the 1990s, though the general trend since the 1970s has been of a significant increase in the number of waterbodies for which states issue mercury-based advisories. For the years 1993-2011 the total lake areas under mercury advisory increased from approximately 3,000,000 acres in 1993 to over 16,000,000 acres in 2011, and the total river miles under such advisories increased from less than 100,000 in 1993 to more than 1,000,000 in 2011, with both numbers peaking in 2008. Like many of the environmental hazards realized during the early 1970s, initial optimism over the potential of federal environment laws to remove those hazards later gave way to the realisation that the environmental impacts of industry are hard to remove from the landscape. For example, some advisories issued in the 1970s were still listed as active into the 2000 s. $^{31}$

The spike in pro-environmental attitudes among the public in the late 1990s led to the Clean Air Act Amendments of 1990, which significantly rewrote the original law and significantly increased the number of air toxics regulated under the Act. The Amendments

${ }^{31}$ Data about water bodies under advisory come from the 2011 edition of the National Listing of Fish Advisories General Fact Sheet (https://www.epa.gov/fish-tech/national-listing-fishadvisories-general-fact-sheet-2011). Information about specific advisories comes from the EPA's National Listing of Fish Advisories database (https://fishadvisoryonline.epa.gov/advisories.aspx). The data discussed applies to mercury specifically, though other areas may be under advisories of other contaminants such as polychlorinated biphenyls (PCBs) and dioxins. 
required major sources of those toxics to use the maximum achievable control technology to limit such emissions. Though coal-fired electric power plants, the largest source of anthropogenic mercury emissions in the United States, would otherwise qualify as a major source under those amendments, the law instead required a series of reports by the EPA and the National Institute of Environmental Health Sciences - in 1999, Congress also required a subsequent report from the National Academy of Science examining the EPA's mercury-related health findings. This led to a surge in government-led scientific research into mercury's health effects; while those studies were concluding, however, reports of a possible new source of mercury risk unanticipated by those reports emerged into the public consciousness in the United States: the mercurial vaccine preservative, thimerasol. ${ }^{32}$

\section{THIMEROSAL AND THE ANTI-VACCINE MOVEMENT IN THE UNITED STATES}

Most medicinal uses of mercury had proven either ineffective or inferior to available alternatives, but its antiseptic properties still had a use. While vaccine use had significantly reduced death and suffering from a variety of formerly-widespread diseases such as pertussis (whooping cough), early vaccines often became contaminated with bacteria, sometimes leading to numerous deaths and illnesses. While many early vaccine preservatives could reduce the

\footnotetext{
${ }^{32}$ For a comprehensive overview of the Clean Air Act Amendments of 1990 by one of their architects, see H. Waxman, “An overview of the Clean Air Act Amendments of 1990," Environmental Law 21 (1991). For a historical account of mercury emissions regulations for coal-fired power plants under the Clean Air Act, see Carter, "Alchemical Rulemaking and Ideological Framing: Lessons from the 40-Year battle to Regulate Mercury Emissions from Electric Power Plants.”
} 
potency of the vaccine itself, researchers at Eli Lilly and Company discovered that an ethylmercury compound it had helped develop, thimerosal, was not only extremely effective as an antibacterial agent at extremely low dosage, but did not negatively impact the biologically active components of vaccines. While some scientists questioned its efficacy, there were few challenges to thimerasol's safety specifically before the late 1990s, and following its introduction, and the introduction of other organomercurial vaccine preservatives, instances of bacterial contamination of vaccine dropped. The FDA conducted a formal review of thimerosal use in biological products in 1976, holding it unlikely that vaccine use would lead to dangerous levels of mercury. ${ }^{33}$

That is not to say, however, that vaccine safety generally was not a contentious issue. Public antipathy to vaccines has been a recurrent phenomenon since vaccines themselves were developed. Anti-vaccination movements sprung up in England in response to compulsory vaccination laws in the mid-1800s, often ideologically similar to contemporary anti-vaccination movements, with their adherents opposing government mandate and professionalized medicine, and supporting both patient choice in medical treatment and the efficacy of alternative, "holistic" medicine. They have reoccurred there and arisen around the world, both in developed and developing countries, across different segments of society. For example, widespread resistance to vaccination programs in the Boston area in the late nineteenth through early twentieth century led to the Supreme Court holding in Jacobson v. Massachusetts that states could mandate

\footnotetext{
${ }^{33}$ J.P. Baker, "Mercury, Vaccines, and Autism: One Controversy, Three Histories," American Journal of Public Health 98 (2008); L.K. Ball et al., "An Assessment of Thimerosal Use in Childhood Vaccines," Pediatrics 107 (2001).
} 
vaccination and publish those who refused them (though not force vaccination). In the 1970s, anti-vaccine sentiment again rose, particularly as it related to the DPT

(diptheria/tetanus/pertussis) vaccine, as media reports of adverse health reactions possibly linked to the vaccine created cycles of increased public anxiety. The 1970s saw significantly reduced vaccination rates in a number of developed countries, including the U.K., Ireland, the Soviet Union, and Australia. A confluence of factors may have caused this, including a countercultural context that saw citizens of developed nations particularly turn against traditional norms of governmental and expert authority, as well as towards formerly unconventional "natural" lifestyle choices that had become increasingly popular among mainstream society. ${ }^{34}$

Historian Elena Conis links American anti-vaccine sentiment of that time at least partially to a second-wave feminist movement that sought to "wrest control of women's health issues from the predominantly male medical profession." In 1982 a TV broadcast entitled DPT: Vaccine Roulette aired across the country, warning viewers of "serious questions about the safety and effectiveness of the [DPT] shot," at one point juxtaposing videos of developmentally disabled children with medical experts arguing over those questions. Shortly after, in 1985, the

${ }^{34}$ N. Durbach, Bodily Matters: The Anti-Vaccination Movement in England, 1853-1907 (Durham, 2005); R.E. Spier, "Perception of Risk of Vaccine Adverse Events: A Historical Perspective," Vaccine 20 (2001); E. Conis, Vaccine Nation: America's Changing Relationship with Immunization (Chicago, 2015); E.J. Gangarosa et al., "Impact of Anti-Vaccine Movements on Pertussis Control: The Untold Story," The Lancet 351 (1998); K. Walloch, “"A Hot-Bed of the Anti-Vaccine Heresy': Opposition to Compulsory Vaccination in Boston and Cambridge, 1890-1905”(PhD diss., University of Wisconsin-Madison, 2007). 
influential vaccine sceptic book DPT: A Shot in the Dark, warned both of possible allergic reactions to the "mercurial preservative" thimerosal in the pertussis portion of the DPT vaccine, and a possible connection between the vaccine and autism generally, though he did not link the two together. ${ }^{35}$

Fears over the pertussis portion of the DPT vaccine, as well as large awards won by litigants against vaccine makers, led to Congress passing the National Childhood Vaccine Injury Act of 1986, which established the National Vaccine Injury Compensation Program (Vaccine Program) providing a fund and procedure for allowing children and their guardians to seek compensation for adverse reactions. Ultimately, however, the vaccine at issue was replaced with a new type, and a number of restrospective studies in the 1990s found no evidence of a causal relationship between it and neurological injury. It was researchers in the United Kingdom, where the anti-vaccine movement had long been stronger and more pervasive than in the United States that focused attention on thimerosal, albeit initially indirectly. A British researcher and physician, Andrew Wakefield, published a paper in the prestigious medical journal The Lancet with a number of co-authors that among other things, purported to show a potential relationship

${ }^{35}$ Conis, Vaccine Nation: America's Changing Relationship with Immunization, 114; H. Coulter \& B. Fisher, A Shot in the Dark (New York, 1985); “DPT: Vaccine Roulette.” NBC, WRCTV, Washington D.C., April 19, 1982. 
between the administration of the mumps/measles/rubella vaccine (MMR) vaccines to children and development of symptoms of a type of autism. ${ }^{36}$

While the article itself was framed conservatively, it quickly came to public attention after a press conference starring Wakefield that would be televised throughout England. While The Lancet paper had suggested that "environmental triggers" might explain chronic bowel abnormalities and developmental disorders, during the press conference Wakefield not only posited a direct MMR-autism connection, but declared he "cannot support the continued use of the three vaccines given together." With tape recorders running, the dean of the hospital, surprised by Wakefield's comments, immediately warned that reducing vaccination rates could lead to child deaths. ${ }^{37}$

The Lancet's editors had already been skeptical of the report by Wakefield and his collaborators, and had taken the unusual step of commissioning a critical analysis of the report before publication by two American vaccine specialists at the Centers for Disease Control which had been published in the same issue as Wakefield's. The authors criticized the report for a number of flaws, including that it was based on cases referred to Wakefield's group, leading to possible selection bias, as well as the paper's reliance on prior studies by Wakefield that later

${ }^{36}$ Conis, Vaccine Nation: America's Changing Relationship with Immunization, 114; A. Wakefield et al., "Ileal-lymphoid-nodular Hyperplasia, Non-Specific Colitis, and Pervasive Developmental Disorder in Children," The Lancet 351 (1998) (retracted Feb. 6, 2010).

${ }^{37}$ D. Flaherty, “The Vaccine-Autism Connection: A Public Health Crisis Caused by Unethical Medical Practices and Fraudulent Science," Annals of Pharmacotherapy 45 (2011); S. Mnookin, The Panic Virus (New York, 2011), 107-108. 
researchers were unable to replicate. Other researchers quickly weighed in to assail the Lancet paper and Wakefield's claims about the MMR-autism link 10 out of 11 of Wakefield's coauthors would later publish a "Retraction of an interpretation" of the Lancet paper, arguing that the paper itself did not establish a causal link between the MMR vaccine and autism because of insufficient data, and retracting any interpretation of such a link. ${ }^{38}$

Neither The Lancet paper nor the press conference contained the word "mercury" or "thimerosal," and the MMR vaccine itself did not even contain thimerosal; why, then, did thimerosal and mercury become so connected with both autism and The Lancet paper in the public mind, particularly in the United States? A number of organisations and researchers had previously questioned whether thimerasol could result in an unsafe level of mercury, including legendary vaccinologist Maurice Hilleman, and the governments of Sweden, Denmark, and Norway had banned thimerosal in vaccines, but such actions had little impact in the United States or United Kingdom. ${ }^{39}$

The source of the connection could be blamed on the United States Congress. The midto-late 1990s saw more attention paid to mercury in American government, particularly

${ }^{38}$ R. Chen \& F. DeStefano, "Vaccine Adverse Events: Causal or Coincidental?" The Lancet 351 (1999); Taylor et al., “Autism and Measles, Mumps, and Rubella Vaccine: No Epidemiological Evidence for a Causal Association,” The Lancet 353 (1999); S. Murch et al., "Retraction of an Interpretation," The Lancet 363 (2004).

${ }^{39}$ Mnookin, The Panic Virus, 131. Hilleman was the most productive vaccinologist in history; for example, he and his laboratory developed vaccines for, among other things, measles, mumps, meningitis, and hepatitis A and B, in forms which are still used today. 
anthropogenic mercury emissions. The Clean Air Act Amendments of 1990 had required the EPA and the National Institute of Environmental Health Sciences to conduct studies of the health impacts of mercury emissions from electric power plants, particularly those that burned coal, which at the time had become the primary source of environmental mercury. During this time, the successful Food and Drug Modernization Act of 1997 required the FDA review mercurycontaining products, including drugs. ${ }^{40}$

The FDA had previously determined benchmark levels of methylmercury at one part per million, above which they could stop the sale of food containing such levels. Vaccine dosages could lead to mercury levels above that; though ethylmercury is less toxic than methylmercury, and while recognizing the importance of vaccines and the lack of evidence of harm, the American Academy of Pediatrics and the United States Public Health Service issued a statement that "because any potential risk is of concern," vaccine manufacturers should eliminate or reduce the amount of mercury in their vaccines. ${ }^{41}$

${ }^{40} \mathrm{Id} ., 121-123$.

${ }^{41}$ K. Joyce, "Is Tuna Safe? A Sociological Analysis of Federal Fish Advisories," in Zuber \& Newman (eds.), Mercury Pollution: A Transdisciplinary Treatment (Boca Raton, 2012); AAP \& USPHS, "Joint Statement of the American Academy of Pediatrics (AAP) and the United States Public Health Service (USPHS)," Pediatrics 104 (1999). While there have been several cases of thimerasol poisoning in the medical literature, all involved amounts far in excess of what is found in appropriate dosages of vaccines, see FDA, "Thimerasol in Vaccines," (2017), 
Anti-vaccine activists, victims, and parents of autistic children, many primed by Wakefield's work, quickly seized upon a potential thimerasol-autism link, despite the lack of any evidence that such a link existed. Even parents who had not previously considered a connection between vaccines and their autistic children seized upon a mercury-autism connection. Wakefield's 1998 claims and the AAP/USPHS call for thimerasol to be phased out of vaccines seemed to be became conflated by many members of the public, despite the fact that the MMR vaccine investigated by Wakefield did not actually contain thimerasol. ${ }^{42}$

While the medical community reacted largely with skepticism to both Wakefield's claims and the AAP/USPHS report, a rapidly organizing anti-vaccination movement in the United States seized on both. At the same time they used the rapidly expanding internet to connect and collaborate with each other. Several such people formed the group SafeMinds; members even published a (non-peer-reviewed) purporting to demonstrate a link between thimerosal and autism. $^{43}$

https://www.fda.gov/BiologicsBloodVaccines/SafetyAvailability/VaccineSafety/UCM096228

${ }^{42}$ Mnookin, The Panic Virus, 138. Wakefield himself would later argue that there was a high likelihood that thimerasol-containing vaccines could also lead to autism, see A. Wakefield, Waging War on the Autistic Child: The Arizona 5 and the Legacy of Baron von Münchausen (New York, 2016).

${ }^{43}$ S. Bernard et al., "Autism: A Novel Form of Mercury Poisoning," Medical Hypotheses 56 (2001). 
As vaccine sceptics and those impacted by autism seized on thimerosal as a likely cause of autism, scientific critiques of Wakefield's work not only grew but quickly turned personal. In 2004, The Lancet issued a statement addressing questions raised over study participant recruitment and Wakefield's role in a pilot project to investigate grounds for a lawsuit brought on behalf of allegedly vaccine-damaged children, finding that Wakefield and his co-authors had been less than transparent in some aspects of their research. Despite significant medical consensus that the MMR vaccine was safe, the public reacted with dismay, and England saw a significant drop in MMR vaccination rates, and a subsequent increase in the number of measles cases, after the Wakefield press conference. Investigative reports that Andrew Wakefield had been funded by - and coordinated with - attorneys contemplating vaccine-related lawsuits, and that there were significant flaws in data collection and analysis methods), would eventually lead to Wakefield losing his license to practise medicine. ${ }^{44}$

Of course, individuals can have negative reactions to vaccines; in 1986 Congress passed the National Childhood Vaccine Injury Act to provide a streamlined, no-fault adjudication of such potentially vaccine-based injuries, largely to protect pharmaceutical companies from large monetary judgments that threatened to drive many vaccines off the market altogether. In the aftermath of The Lancet article, autistic children and their parents and guardians in the United

${ }^{44}$ R. Horton, "A Statement by the Editors of the Lancet," The Lancet 363 (2004); Flaherty, "The Vaccine-Autism Connection: A Public Health Crisis Caused by Unethical Medical Practices and Fraudulent Science"; B. Deer, "MMR: The Truth Behind the Crisis," The Sunday Times (Feb. 22, 2004). For the General Medical Council's decision regarding Wakefield's research, see General Medical Council, Fitness to Practise Panel Hearing (2010). 
States poured into that court. Faced with thousands of petitioners now claiming that MMR and thimerosal-containing vaccines had caused autism, in 2002 the court set up an Omnibus Autism Proceeding that took in a handful of test cases to first establish whether the MMR vaccine and/or thimerosal-containing vaccines could be legally shown to cause autism. The test cases went on for years, while the remaining autism claims waited for their resolution. On February 12, 2009, the Special Master hearing the case concluded that there was no thimerasol-autism link; on August 27 of the following year, the United States Court of Appeals for the Federal Circuit affirmed the Special Master's decision, bringing the Omnibus Autism Proceedings as they related to the thimerasol-autism link to an end. ${ }^{45}$

Did the dramatic media accounts of the effects of environmental mercury in the early 1970s drive at least some of the sentiment behind the thimerasol-related anti-vaccine movement? Baker suggests the anti-vaccine movement's focus on thimerosal was driven partially by the history of poisoning events such as Minamata, along with a lack of public knowledge as to the chemical properties of mercury; he notes that "[p]erhaps unfairly, history has endowed mercury in all of its forms with a notoriety that is not easy to erase."46

Indeed, an entire industry of books skeptical of vaccine safety have sprung up in the past two decades after the Wakefield and AAP/USPHS announcements, both before and after The Lancet retraction, with authors advocating things ranging from modifying typical vaccination schedules for young children all the way to outright avoidance of all vaccines. Such books are

\footnotetext{
${ }^{45}$ Cedillo v. Secretary of Health and Human Services, 617 F.3d 1328 (D.C. Cir. 2010).

${ }^{46}$ J. Baker 2008, "Mercury, Vaccines, and Autism: One Controversy, Three Histories," American Journal of Public Health 98 (2008).
} 
often framed as "how-to" guides for parents and soon-to-be-parents. Many prominent antivaccine authors and advocates have invoked Minamata in their argument against thimerasol in published works. Similarly, posts on a popular antivaccination site, ageofautism.com, reveal numerous references not just to the Minamata poisoning itself but also the response of Japanese governmental and industrial officials who downplayed, lied, or intimidated the Minamata victims, with suggestions that they - the antivaccination activists - are in the same situation, victims of government cover-ups and malice. ${ }^{47}$

For many antivaccination believers, therefore, poisoning events like Minamata are not linked solely to thimerosal danger by mercury alone but also to government and industry forces

${ }^{47}$ For example, Kirby argued that the symptoms seen in Minamata victims were similar to autism. D. Kirby, Evidence of Harm: Mercury in Vaccines and the Autism Epidemic (New York, 2005), 258. Olmsted and Blaxill even suggest that the Niigata mercury poisoning itself may have led to an autism outbreak in area children. D. Olmsted \& M. Blaxill, The Age of Autism: Mercury, Medicine, and a Man-Made Epidemic (2010). Cave and Mitchell argue experts must look to Minamata for data on what thimerasol can do to the body. S. Cave \& D. Mitchell, What Your Doctor May Not Tell You About Children's Vaccines," (New York, 2001). Kennedy (2015) and Geier et al. (2007) invoke the poisonings in Minamata, Iraq, and Ghana to highlight mercury's risk. R. Kennedy, Let the Science Speak (New York, 2015). Regarding accusations of government malfeasance, see, for example, L. Conte, "Autism and the Echo of Minamata's Mercury Tragedy," (2014), http://www.ageofautism.com/2014/01/autism-and-the-echo-of-minamatas-mercurytragedy.html. 
working together to sacrifice human health (and most egregiously child health) for financial expediency. Power disparities (or perceived power disparities) drive risk perception; the fact that the "establishment" - whether the government, the medical profession, or the pharmaceutical industries - has pushed vaccines is therefore sometimes offered as evidence of their danger. The transitive cultural models of physical phenomena - like the intransitive mercury - therefore often involve social or cultural factors that should have no impact on the physical or biomedical characteristics of the substance. But conceptions of disease and suffering involve what the medical anthropologist Sherine Hamdy has referred to as "political etiologies," where "the ways in which people make sense of illness are inevitably political moves that either ignore or speak to power." 48

For many of its immediate or familial victims, autism is thus only made sense of as something that was done to the victim by external forces, and it was easy to blame such forces when they have a history of ignoring health and environmental impacts on the public. Such scapegoating appears to be an inherent characteristic of human psychology. For example, Rothschild et al. have developed a dual-motive model of scapegoating that posits that such scapegoating "can serve two meaningfully distinct motives: (a) maintaining perceived personal value by minimizing feelings of guilt over one's responsibility for a negative outcome and (b) maintaining perceived personal control by obtaining a clear explanation for a seemingly

${ }^{48}$ S. Hamdy, "When the State and Your Kidneys Fail: Political Etiologies in an Egyptian Dialysis Ward," American Ethnologist 10 (2008), 563. 
inexplicable negative outcome ..."49 Vaccines can serve both functions when it comes to autism, a disease simultaneously inexplicable but thought to have some sort of genetic component. As Spier notes, "[t]he anti-vaccine movement derives its strength from intellectual currents that are deeply embedded in the human condition." 50

Unsurprisingly, then, the removal of thimerosal from almost all childhood vaccines in the United States, and the final rulings in the Omnibus Autism Proceedings, have not stopped cases still claiming thimerasol-laden vaccines caused autism. In a nation where most infants receive multiple vaccinations, for any given subset of children exhibiting early onset diseases they are likely to have received a vaccination in the relatively recent past. For parents who must deal autism day-to-day, external scapegoats may assuage conscious or subconscious guilt. For some parents, alternatives to vaccine-caused injury may be too unbearable to accept; in one recent Vaccine Program case, a mother blamed vaccines for her son's death, despite evidence that his death was a result of asphyxia because she co-slept with him. ${ }^{51}$

${ }^{49}$ Z. Rothschild, M. Landau, D. Sullivan, \& L. Keefer, “A Dual-Motive Model of Scapegoating: Displacing Blame to Reduce Guilt or Increase Control," Journal of Personality and Social Psychology 102 (2012).

${ }^{50}$ R. Spier, "Perception of Risk of Vaccine Adverse Events: A Historical Perspective," Vaccine 20 (2001).

${ }^{51}$ See, e.g., Hardy v. Secretary of Health and Human Services from the Vaccine Claims Court. Opinions and orders from that Court can be accessed at http://www.uscfc.uscourts.gov/vaccine-programoffice-special-masters; Pelton v. Secretary of Health and Human Services (2017) (accessible at website identified in the previous note). 
One consistent theme throughout anti-vaccine texts (including court filings) is a resistance to genetic reductionism, with the belief that while susceptibility to vaccine-born mercury may have a genetic component, that some environmental factor - like a vaccine - must play a part. Parents who accept genetic explanations sometimes blame themselves for that gene expression. $^{52}$

By identifying thimerosal, anti-vaccine activists and believers were able to call on cultural models of risk that may have combined not only risk models engrained in the aftermath of Silent Spring and Minamata, but also a growing antipathy towards expertise and authority; one popular vaccine book encapsulates all of the above in its title, Vaccine Epidemic: How Corporate Greed, Biased Science, and Coercive Government Threaten Our Human Rights, Our Health, and Our Children. ${ }^{53}$

${ }^{52}$ Hardy v. Secretary of Health and Human Services from the Vaccine Claims Court. Opinions and orders from that Court can be accessed at http://www.uscfc.uscourts.gov/vaccineprogramoffice-special-masters; Pelton v. Secretary of Health and Human Services (2017) (accessible at website identified in the previous note); Boyle et al. 2006; C. Decoteau \& K. Underman, “Adjudicating Non-Knowledge in the Omnibus Autism Proceedings," Social Studies of Science 45 (2015).

${ }^{53}$ Habakus \& Holland (eds) 2011. The book is published by Skyhorse Press, which publishes numerous books linking vaccines to autism and other adverse health impacts, including several of the anti-vaccination books cited herein. See http://www.skyhorsepublishing.com/search?q=vaccine $\% 22 \& \mathrm{f}=1$. 
In his book Callous Disregard: Autism and Vaccines, the Truth Behind a Tragedy, Wakefield himself characterized his story as one of "how the powerful deal with threats to their interests." Just as unrestrained industry had poisoned formerly clean land, water, and organisms with mercury, unrestrained industry had poisoned young children and stolen not just something physical but through autism something of their very mental essence. Such a charge is leveraged by not just Minamata but innumerable events of industrial crimes in the United States and abroad; why should activists believe the government and medical-industrial complex now when they have demonstrably misled the public on so many occasions before? Individual provaccination medical practitioners often receive little more credibility in the minds of antivaccination activists; their engagement with the medical profession as a whole is tinged with failure and disappointment: there is no known cure for autism. ${ }^{54}$

Deeply contextualized, cultural models "once learned, cannot be easily unlearned." Models of mercury perception that see thimerasol as poison are buttressed by both political etiologies based on institutional distrust and historical accounts of mercury's poisonous effects. That may help explain why neither the overwhelming scientific consensus that thimerasol is safe, nor the fact that it has been removed from almost all childhood vaccines (including the DPT vaccine) - and that it was never in the MMR vaccine in the first place - has done much to reduce the fervor of anti-vaccine activism in the United States. Some anti-vaccine activists have focused

${ }^{54}$ A. Wakefield, Callous Disregard: Autism and Vaccines -The Truth Behind a Tragedy (New York, 2017).

${ }^{55}$ S. Atran, D. Medin \& N. Ross, "The Cultural Mind: Environmental Decision Making and Cultural Modeling Within and Across Populations," Psychological Review 112 (2005), 24. 
their anger on influenza vaccines, the multi-dose versions of which still may contain thimerasol. ${ }^{56}$ Others have simply proposed that non-thimerosal forms of mercury can cause autism, such as emissions from coal combustion or mercury dental amalgams. ${ }^{57}$ Some have also begun to advocate for removing thimerosal for vaccines in the developing world where it may still be used frequently due to lack of refrigeration. ${ }^{58}$

As Forrester recognized long ago, mental models are "fuzzy ... incomplete . . . [and] imprecisely stated." Ultimately, the intransitive reality of the MMR vaccine is that it does not contain mercury and is not linked to autism; the transitive cultural model of the vaccine is not so limited. The temporal proximity of the Wakefield paper and the AAP/USPS call for vaccine manufacturers to remove thimerasol from their formulations may have simply become

${ }^{56}$ See, e.g., the Moms Against Mercury website at http://momsagainstmercury.org/doctorsquestion-flu-shot-statistics.htm.

${ }^{57}$ See, e.g., id., and the SafeMinds website at https://www.safeminds.org/mercuryautism/environmental-mercury/coal/ and the Moms Against Mercury website (http://momsagainstmercury.org/mercury-in-the-environment.htm and http://momsagainstmercury.org/mercury-dental-fillings.htm. Though environmental mercury through fish consumption or other routes can likely cause neurodevelopmental problems, there is little evidence that autism is one of them.

${ }^{58}$ M. Ashton, P. Kohler \& K. Xia, "Summary of the Second Meeting of the Intergovernmental Negotiating Committee to Prepare a Global Legally Binding Instrument on Mercury: 24-28 January 2011," Earth Negotiations Bulletin 28 (2011); K. Barry, Vaccine Whistleblower: Exposing Autism Research Fraud at the CDC (New York, 2015), Ch. 7. 
intertwined for many anti-vaccine believers and activists. That the vaccines at issue may not have mercury in many cases is besides the point; cultural models are by definition simplified representations of the real world, and constrained by evolutionary limitations of the human brain. Dealing with the biomedical complexities of vaccines may simply result in many cases in a model that reduces vaccine risk to mercury, and mercury to the toxic form which caused so much damage to the victims of Minamata. ${ }^{59}$

The impact of the recent thimerasol-driven anti-vaccination movement is uncertain. Looked at broadly, overall vaccination rates in the United States (including vaccines that formerly had thimerasol) have tended to remain stable, both before and after The Lancet paper and the APA/USPHS statement. ${ }^{60}$. However, those rates can hide high vaccination refusal rates at the local level; several areas of the country have seen sharp decreases in their vaccination rates leading to outbreaks. For example, pertussis cases (whooping cough) increased significantly in the early 2000s, going from 7,580 in 2001 to over 25,000 in the years 2004-2005, and peaking at 48,277 in 2012. The impact of mandated vaccination laws at the state level (or the relaxing of such laws) can also impact vaccination rates. ${ }^{61}$

\section{Conclusion}

Humanity has grown up with mercury, from simple cave drawings using cinnabar to modern liquid mirror telescopes using mercury as a reflective mirror. Alternately potent and

\footnotetext{
${ }^{59}$ J. Forrester, "Counterintuitive Behavior of Social Systems," Theory and Decision 2 (1971),
} 112.

${ }^{60}$ See the Child Trends database at https://www.childtrends.org/indicators/immunization/.

${ }^{61}$ See the CDC VaxView at https://www.cdc.gov/vaccines/vaxview/. 
dangerous, its shifting, liquid physicality serves as a metaphor for its own role in human history. But mercury as a historically constituted cultural model is not just driven by perceptions (and misperceptions) of its physical and chemical impacts; drawn into those models are conceptions of modern industrial society and technocratic authority that impact mercury's biophysical impact in the minds of those who must deal with it.

Cultural models of mercury change but also retain old concepts. Mercury as remedy may have been mostly purged from the corpus of acceptable medicine outside vaccine use, but it still maintains an important part of folk medicines outside of modern medicine. Mercury-containing medicine can be found in ethnic enclaves in the United States, including in Chinese herbal remedies and in the botanícas serving Caribbean communities where mercury-based medicinals are sold to followers of the indigenous Caribbean religions espiritismo, voudoun, and Santeria. Religious use of mercury-containing products can range from the relatively benign practise of carrying it around in sealed pills for luck to highly-dangerous injections of it to "ward off evil." On the other side of the mercury risk chasm, anti-vaccine activists imbue safe levels of thimerasol with the unsafe characteristics of the more toxic methylmercury, seeing them as harmful agents of an unfeeling, profit-driven government-medical-industrial complex. ${ }^{62}$

\footnotetext{
${ }^{62}$ G. Wong, "Mercury and Chinese Herbal Medicine," British Columbia Medical Journal 46 (2004); L. Zayas \& P. Ozuah, "Mercury use in Espiritismo: A Survey of Botanicas," American Journal of Public Health 86 (1996); M. Ojito, "Ritual Use of Mercury Prompts Testing of Children for Illness,” The New York Times (Dec. 14, 1997); V. Prasad, “Subcutaneous Injection of Mercury: 'Warding Off Evil'," Environmental Health Perspectives 112 (2004), 1326.
} 
Though emissions controls have improved, the rapidly increasing number of coal-fired power plants in the developing world, especially China and India, have become a major source of anthropogenic mercury. At the same time, increases in global gold prices have led to a massive increase in the use of mercury in small-scale artisanal gold mining in the developing world, which now makes up the largest anthropogenic source of mercury on a global level. Using techniques not much more advanced than that used thousands of years ago to purify mined materials of non-gold elements, and often working on legal and societal fringes, artisanal gold miners and refiners risk not only mercury inhalation risk but also discharge large amounts into the environment. ${ }^{63}$

As a result, governments around the world are engaging with mercury risk at an unprecedented level. For example, representatives of over 100 countries around the world signed the Minamata Convention on Mercury on October 10, 2013. The Convention is a global treaty that when in force will impose binding obligations on its signatories to, among other things, reduce anthropogenic mercury emissions to the environment and address mercury's risk to human populations. After economic development largely unrestrained by environmental considerations, China, one of the largest emitters of mercury, implemented a comprehensive mercury mitigation plan in 2012. In the United States, almost 40 years of debates over the regulation of mercury emissions from coal-fired power plants, the country's most significant anthropogenic source since at least the early 1990s, came to an apparent end when the EPA

${ }^{63}$ United Nations Environment Programme, "Minamata Convention on Mercury,” TIAS No. 17816 (2013). 
finalized rules regulating such emissions. The comment period for the proposed rule drew over 700,000 public comments, most in support of the rule. ${ }^{64}$

But policy initiatives to deal with environmental risk cannot ignore that risk is a social construction. Scientific models of mercury actions and mechanisms may become more accurate, but that does not necessarily mean that cultural models will follow. Legal and regulatory efforts to protect human beings not only from mercury but also from infectious diseases that vaccines prevent are subject to seemingly irrational reasoning and decision-making that have either overestimated mercury's risk or underestimated it for too many people. Mercury fish advisories have been issued since the 1970s in the United States, but there is significant noncompliance with such advisories, leading to potentially unsafe consumption habits, particularly in poor communities and communities of color. ${ }^{65}$

This is not unique to mercury; the transitive cultural models about climate change, about other contaminants, and about other health risks have proven difficult to change; the rationalist "information deficit" approaches to improving public decision-making, which assumes that the solution to inaccurate reasoning is to provide better scientific information, has proven severely

${ }^{64}$ Most public comments were published on the EPA's rulemaking docket at https://www.regulations.gov/docket?D=EPA-HQ-OAR-2009-0234.

${ }^{65}$ See, e.g., G. Beehler, B. McGuiness \& J. Vena, "Perception of Risk: Contextualizing African American Anglers' Sport Fishing Practices," Human Organization 60 (2001). 
flawed. Cognitive scientific frameworks like cultural models offer a theory of reasoning that seem to more accurately explain how humans actually reason. ${ }^{66}$

However, current cultural/mental models approaches to human-environment interactions have tended to focus on creating "snapshot" models that elicit and report mental models of specific groups at a specific place in time, with the focus of improving decision-making processes by both individuals and groups. But as such models are historically constituted, understanding the processes by which people understand, reason, and make decisions about environmental hazards could benefit from historical perspectives that examine the transmission of knowledge over time. Such an interdisciplinary approach to environmental cultural models could result in better historical analysis as well as better environmental decision-making research that can inform policy improvements and create healthier outcomes for the public.

${ }^{66}$ S. Owens, “'Engaging the Public': Information and Deliberation in Environmental Policy,” Environment and Planning - Part A 32 (2000). 